\title{
Enhancing reliability of electricity supply of city electric networks cities of Dushanbe
}

\author{
Alexander Ivanovich Sidorov, Saidjon Tavarov \\ Polytechnic Institute, Faculty of Mechanical Engineering, Department of Life Safety, South Ural State University \\ (National Research University), Russian Federation
}

\section{Article Info \\ Article history: \\ Received Jan 3, 2020 \\ Revised Mar 15, 2020 \\ Accepted May 16, 2020}

\section{Keywords:}

City electric networks Power consumption Power supply reliability Smart power metering

\begin{abstract}
The article is devoted to the actual problem of how to improve the reliability of the urban electric network. Based on the statistical analysis of the breakdown of electrical equipment in urban distribution networks in Dushanbe for the periods of 2017-2018 and for the reasons of damage leading to these emergency outages, the factors that affect the distribution of damage leading to emergency outages are identified. Taking into account the identified factors, a power consumption forecasting system is proposed that takes into account the local conditions of the city of Dushanbe. it allows us to suggest a way to control the operating parameters of the electric network, thereby increasing the reliability of the city's electric network in Dushanbe based on the recommendation of power consumption standards. Implementation of the control of the proposed method for improving the reliability of power supply to the urban electric network is proposed on the basis of the functionality of modern smart electricity metering using the control algorithm. To implement the control algorithm, schematic design for receiving and transmitting information from smart power metering to the data collection centre is proposed.
\end{abstract}

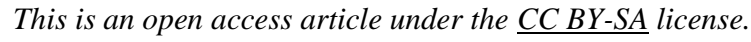

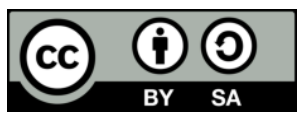

\section{Corresponding Author:}

Saidjon Tavarov,

Polytechnic Institute, Faculty of Mechanical Engineering, Department of Life Safety,

South Ural State University (National Research University),

454080 Chelyabinsk, Lenin Avenue, 76, Russia.

Email: bgd-susu@mail.ru

\section{INTRODUCTION}

The effectiveness of any electrical networks, including city networks, is ensured by maintaining the allowable specific loads, both at maximum hours and throughout the day and month. Exceeding specific loads from the normative leads to a deterioration in the reliability of the power supply system [1-18]. The efficiency of the power supply system depends on the correct forecast of power consumption. Under the concept of efficiency is understood - the reliability of power supply. In turn, the reliability refers [16-18]:

- power quality

- service life of electrical equipment

- lack of electricity supply

The increase in electrical load is associated, in particular, with the climatic and meteorological conditions of the area and in the absence of warm-hot water supply for urban consumers, this factor may be the main reason for the increase in electric load, which subsequently can lead to a violation of the quality of electric power and the life of electrical equipment and undersupply of electricity. It should be noted that consumers in Dushanbe, like the whole Republic of Tajikistan, are deprived of other sources and the entire load lies on the shoulder of electricity. To increase the reliability of Dushanbe city networks, it is necessary 
to identify factors affecting damage to the main elements of the power supply system with the aim of proposing a method and method of increasing the reliability of power supply to the city electric network using the example of Dushanbe.

\section{STATEMENT OF THE PROBLEM}

To assess the reliability of power supply to the city electric network in Dushanbe according to the statistics of emergency shutdowns for the periods 2017-2018. dependencies were built and analysis was carried out in order to identify the influence of the above factor on the amount of damage to cable, overhead lines and transformer substations with a voltage of $6-10 / 0.4 \mathrm{kV}$ of the city electric network in Dushanbe. To propose a method and method for increasing the reliability of power supply of the city electric network in Dushanbe.

It should be noted that the coldest month for Dushanbe is January. The average air temperature in the winter months ranges from 2 to $4^{\circ} \mathrm{C}$. During this period, mostly cloudy and rainy weather caused by cyclonic activity prevails. As a rule, the passage of the cyclone ends with a cold invasion, a sharp decrease in air temperature and the transition of rain into wet snow. With increased anticyclonic activity, cold air spreads to Dushanbe in the southwestern periphery of the Siberian anticyclone, which causes significant cooling. In abnormally cold years, air temperature can drop to $-27^{\circ} \mathrm{C}$.

However, winters with a minimum temperature of $5 \ldots-10^{\circ} \mathrm{C}$ have the most repeatability. During the day, as a rule, the air temperature is positive and amounts to $7-10^{\circ} \mathrm{C}$ heat. In the warmest winters, the maximum air temperature can reach $22^{\circ} \mathrm{C}$ in January. Spring in Dushanbe is warm and rainy. Cyclonic activity in the spring is particularly intense and is accompanied by heavy rainfall with thunderstorms and hail. In March and April, the highest rainfall occurs (up to $135 \mathrm{~mm}$ per month). The highest daily maximum occurs in spring and exceeds $80 \mathrm{~mm}$.

According to the statistics of emergency shutdowns of overhead lines, overhead lines and transformer substations with a voltage of 6-10 kV, the dependencies were constructed, presented in Figures 1 and 2. According to Figures 1 and 2 the most damaged elements in the autumn-winter and winter-spring periods are cable power lines and transformer substations. This, from our point of view, is associated with an increase in electricity consumption in the autumn-winter period due to the absence of other sources of energy besides electric, and an increase in precipitation in the winter-spring period caused by rains and melting snow. To identify the causes of damage leading to emergency shutdowns Figures 1 and 2, we constructed the distribution diagrams of the violation according to the types of damage Figures 3 and 4. This will allow a more detailed assessment of the factors affecting damage and, on the basis of them, suggest ways to improve the reliability of power supply, taking into account the influence factors.

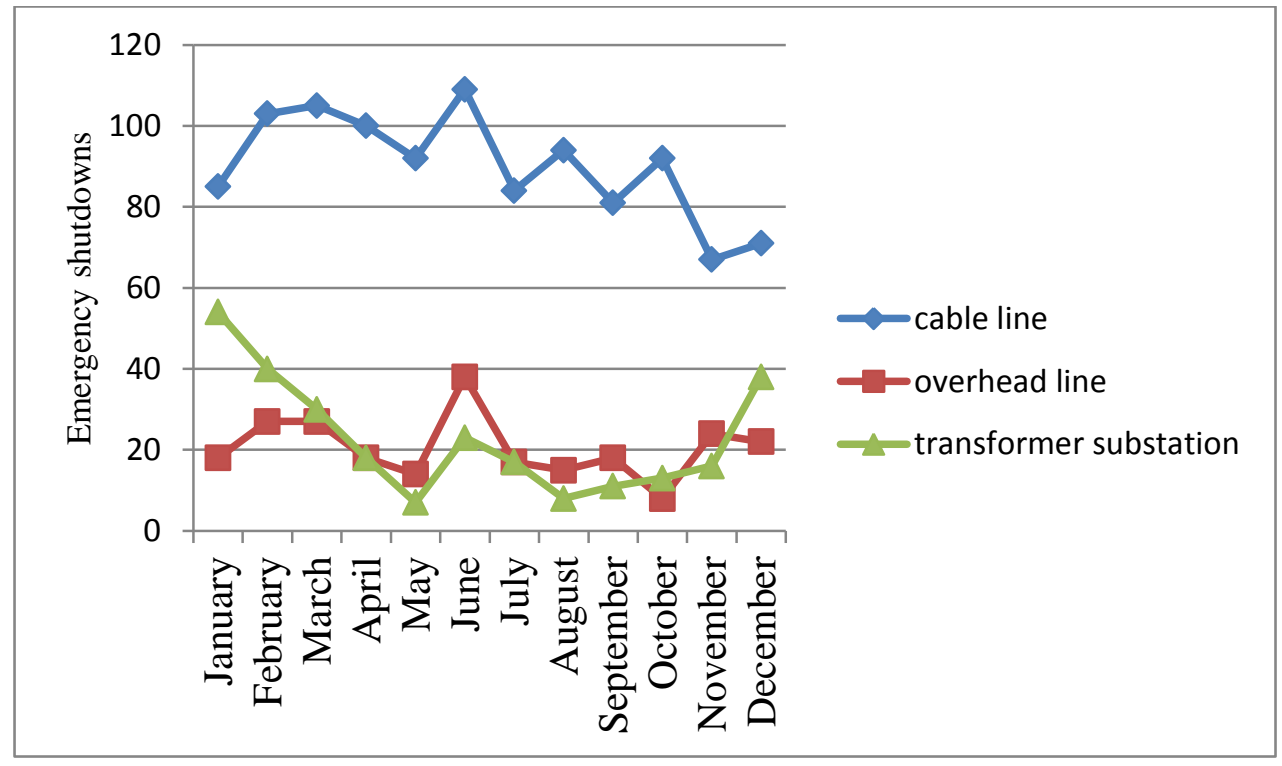

Figure 1. Monthly crash statistics for 2017 


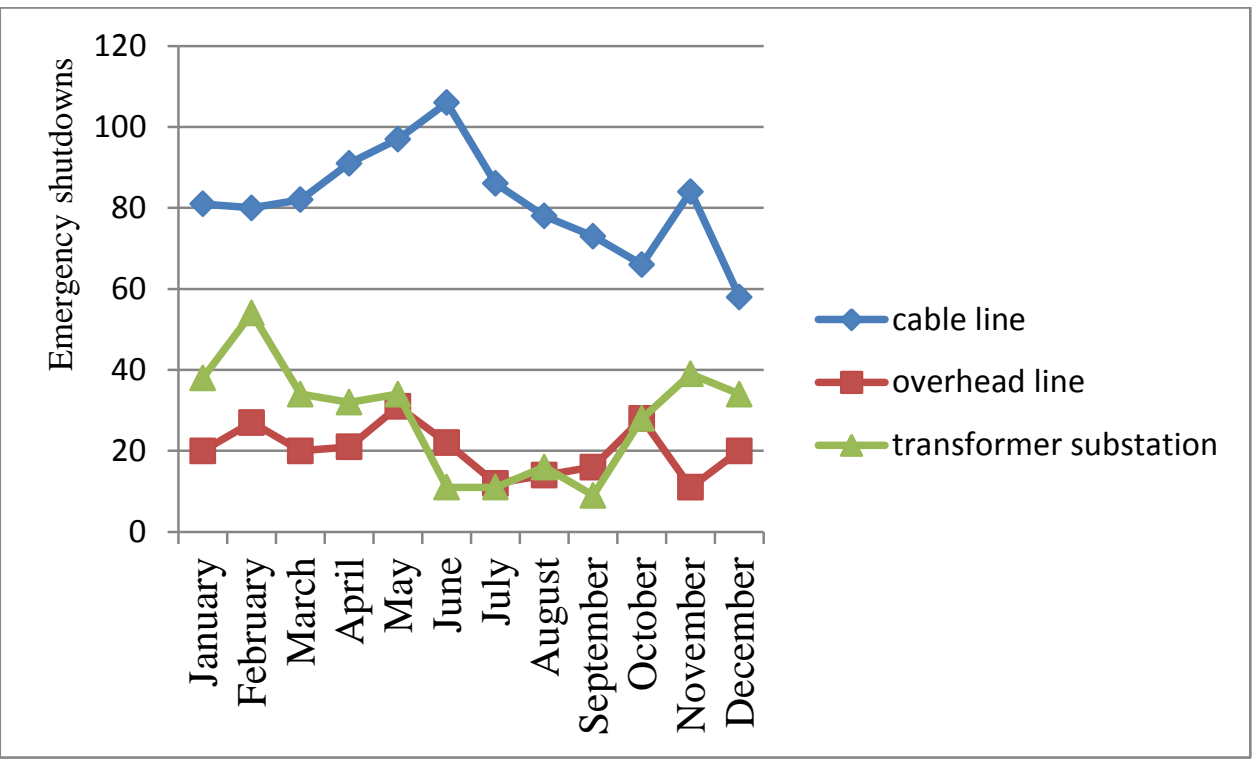

Figure 2. Monthly crash statistics for 2018

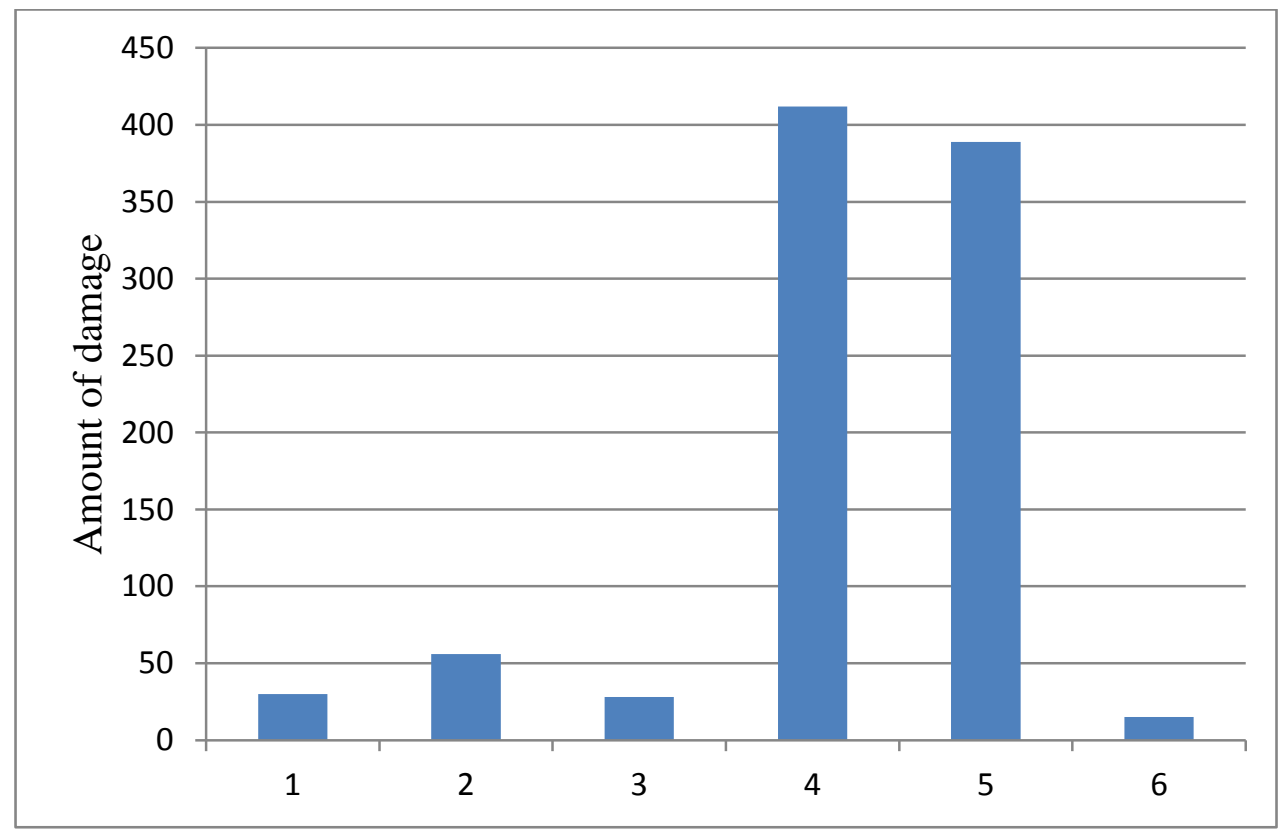

Figure 3. Distribution of cable damages of 6-10 kV due to the causes of their occurrence in 2018

In Figure 3 shows the distribution of damage on cable lines (CL) of 6-10 kV distribution electric networks in Dushanbe. The following notation is accepted here:

a. Violation of the structure of the material of the installation, its parts or assemblies

b. Thermal damage, overheating, burnout

c. Arc damage

d. Violation of electrical insulation

e. Violation of electrical contact

f. No reasons identified

According to Figure 3, the greatest amount of damage on a $6-10 \mathrm{kV}$ cable line was caused by a violation of electrical insulation and electrical contact. 


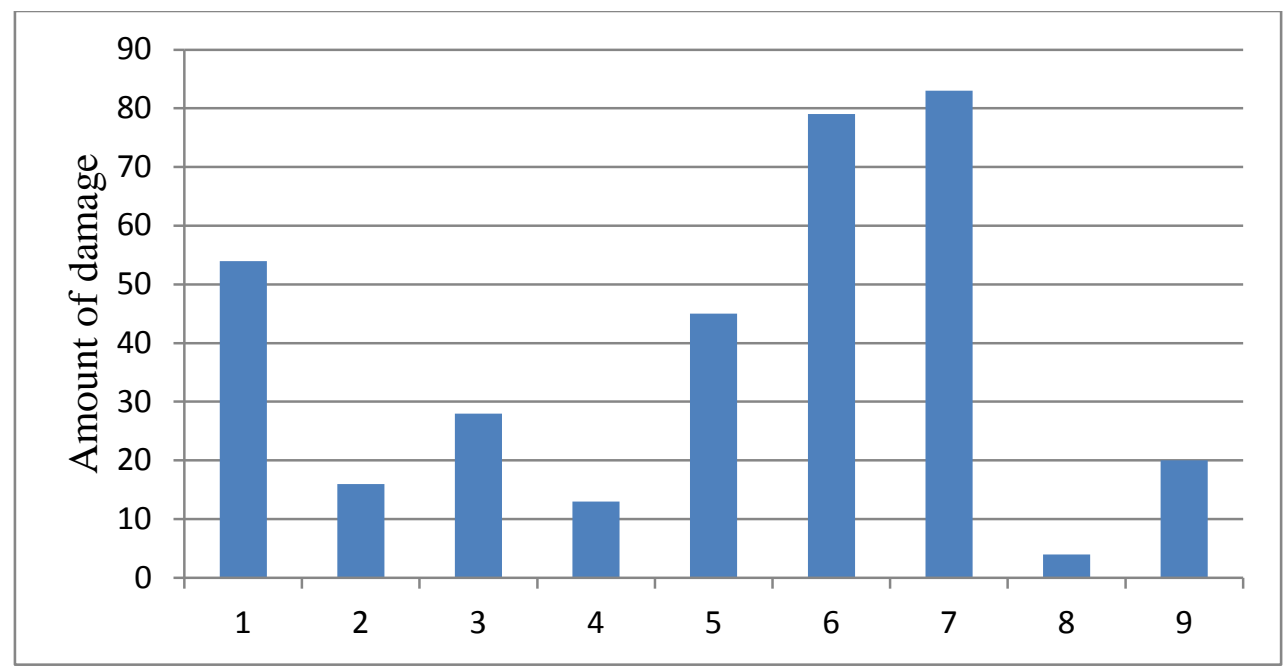

Figure 4. Distribution of damage to transformers 6-10/0.4 kV due to the reasons for their occurrence in 2018

In Figure 4 shows the distribution of damage on a 6-10/0.4 kV transformer substation of distribution networks in Dushanbe. The following notation is accepted here:
a. Violation of the structure of the material of the installation, its parts or assemblies
b. Violation of welding, soldering
c. Violation of the mechanical connection
d. Corrosion wear
e. Arc damage
f. Violation of electrical insulation
g. Violation of electrical contact
h. Sunbathing or fire

i. Unclassified reasons

According to Figure 4, the greatest amount of damage at a 6-10/0.4 kV transformer substation was caused by a violation of electrical insulation and electrical contact. From the obtained diagrams Figures 3 and 4 , the effect of electric load on the damage to cable lines and transformer substations is visible. This is proved by the causes of the damage. To assess the impact of climatic and meteorological conditions in Dushanbe, the dependences of monthly average temperatures and precipitation were plotted Figures 5 and 6. This assessment allows us to identify the influence of the factor of terrain conditions on the amount of damage leading to emergency outages.

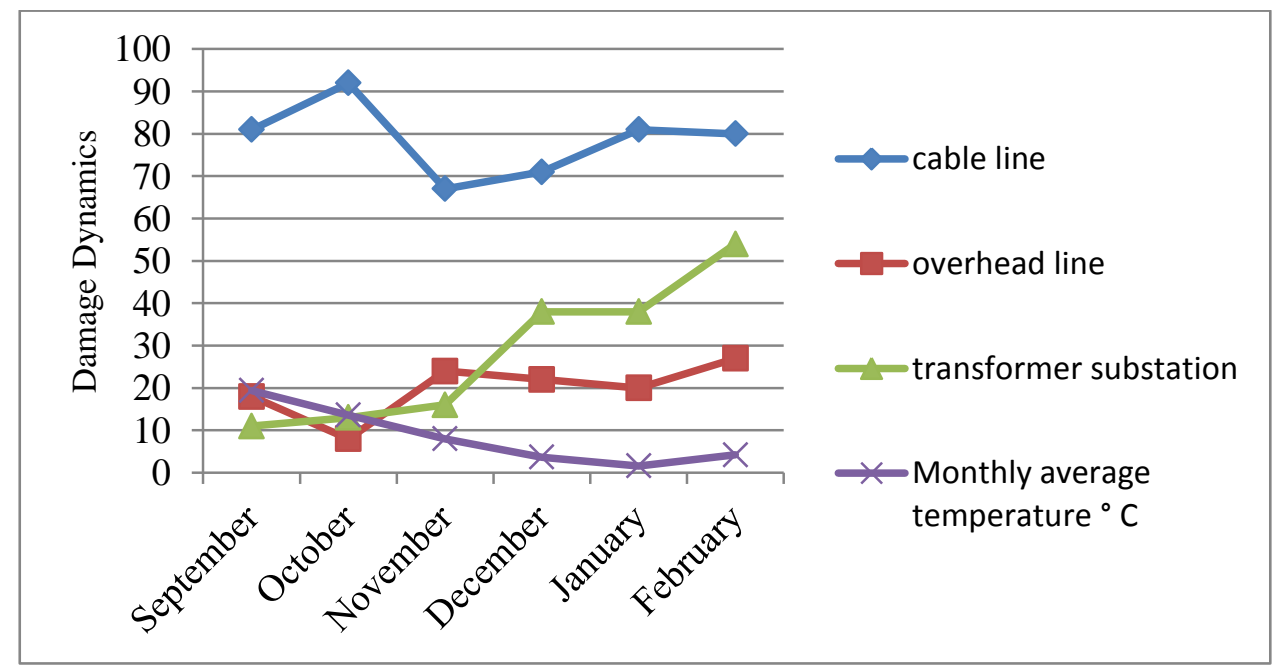

Figure 5. The effect of average monthly air temperature on the dynamics of damage in the autumn-winter period of 2017-2018 


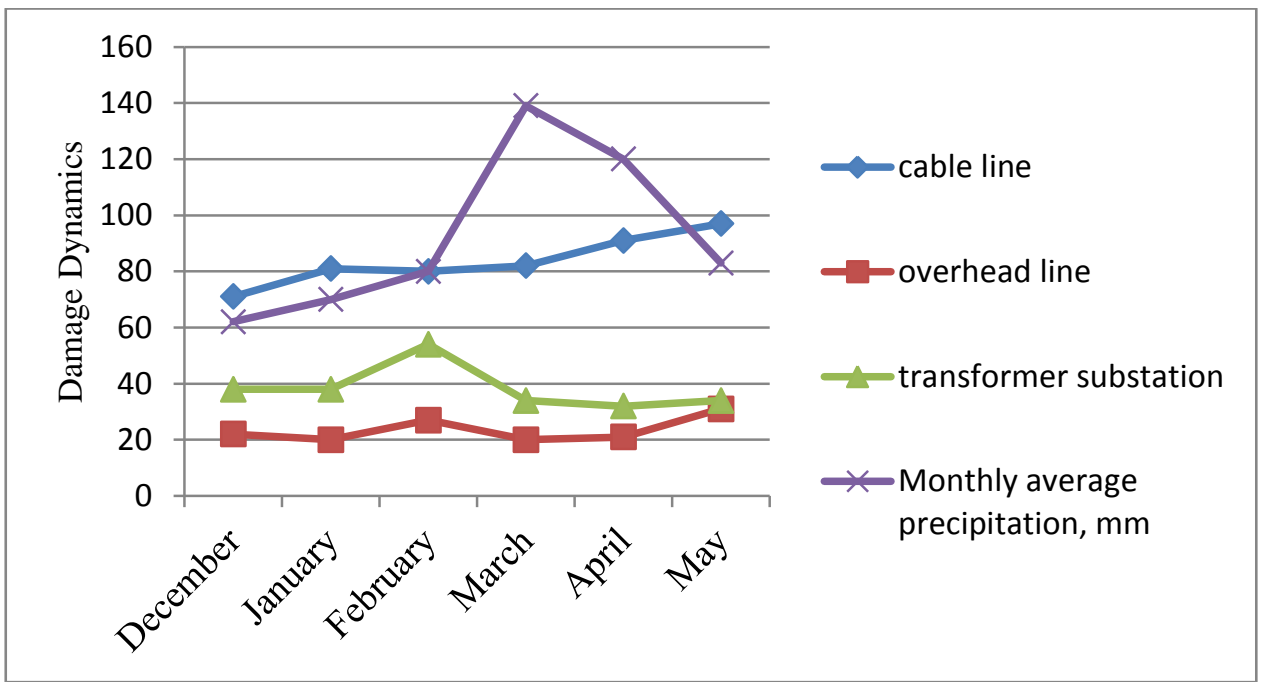

Figure 6. The effect of monthly average precipitation on the dynamics of damage in the winter-spring period of 2017-2018

From the obtained dependence of Figures 5 and 6 it is seen that in the autumn-winter period, with a decrease in the average monthly temperature, the amount of damage to the considered elements of the city electric network, especially in cable lines and transformer substations, increases, as noted above, the main factor is the increase in electricity consumption by urban consumers leading to overheating of cable cable veins and transformer windings associated with overloads and further breakdown of insulation, as well as changing climatic and meteorological conditions of the area in this uchae Dushanbe. Therefore, when developing a program to improve the reliability of urban distribution networks with a voltage of $6-10 \mathrm{kV}$, it is necessary to take into account the power consumption and climatic and meteorological conditions of Dushanbe.

\section{RESEARCH METHOD}

In this paper, a method of forecasting the electricity consumption is proposed for household consumers in Republic of Tajikistan (RT) with the aim of regulation of regime parameters of urban electrical grids by operational dispatch ing service. A method of forecasting was compiled on the basis of equations with considering a coefficient of time maximum load $-\alpha_{t . m . l .}$, which was obtained for different cities of RT $[1,2,13]$ and which has functional dependence:

$$
\begin{aligned}
& \alpha_{t . m . l .}=f\left(x_{i}\right), \\
& x_{i}=x_{1} ; x_{2} ; x_{3} ; x_{4} ; x_{5},
\end{aligned}
$$

where; $x_{1}=$ a temperature; $x_{2}=$ features of building structure; $x_{3}=$ a difference of height above sea level between locations of cities; $x_{4}=$ an air humidity: $x_{5}=$ a wind speed.

The equation of forecasting the electricity consumption with considering a factor condition of cities in RT in time of maximum electric load and during the whole day is provided below:

$$
W_{\alpha_{t . m . l .}+1}=W_{\text {daily rate }} \cdot \alpha_{t . m . l .} \cdot\left(1-\alpha_{t . m . l .}\right)
$$

where: $W_{\text {daily rate }}=P_{\text {per.power }} \cdot t_{\text {в.м.сут. }}=$ a daily electric energy consumption rate, $\mathrm{kWh} ; t_{\text {t.m.day. }}=\mathrm{a}$ time $P_{\text {per.power }}=$ a permitted power which is outputted by energy supply organization $(4-5 \mathrm{kWh})$; of maximum electric load during the whole day, h., $\alpha_{t . m . l}=$ a coefficient of time maximum load.

The obtained equation makes it possible to forecast, plan and control norms of electric energy consumption $[1,2,13]$ without violation of established norms of specific loads and hence it will contribute to increase the reliability of electricity supply and electricity quality. To compare with the experimental values, we perform the calculation using the above (3) for household consumers in Dushanbe, taking into account 
the territorial and climatic meteorological conditions. We want to note that this (3) allows us to predict, plan and control electricity consumption for other household consumers of cities of the Republic of Tajikistan.

For the city of Dushanbe (the capital of the Republic of Tajikistan, located at an altitude of $706 \mathrm{~m}$ above sea level):

$$
W_{\alpha_{t . m . l .}+1}=96 \cdot 0,145 \cdot(1-0,145)=11,902 \mathrm{kWh}
$$

According to the data of electricity consumption for the previous period in Figure 7 shows the results of a comparison of the calculated (3) and experimental values. According to Figure 7 the equation of forecasting the electricity consumption (3) is adequate. Using modern smart electricity metering [19-25], it is possible to monitor the state of electric networks in our cases, the proposed energy consumption standards for Dushanbe and the cities of the Republic of Tajikistan $[1,2,13]$.

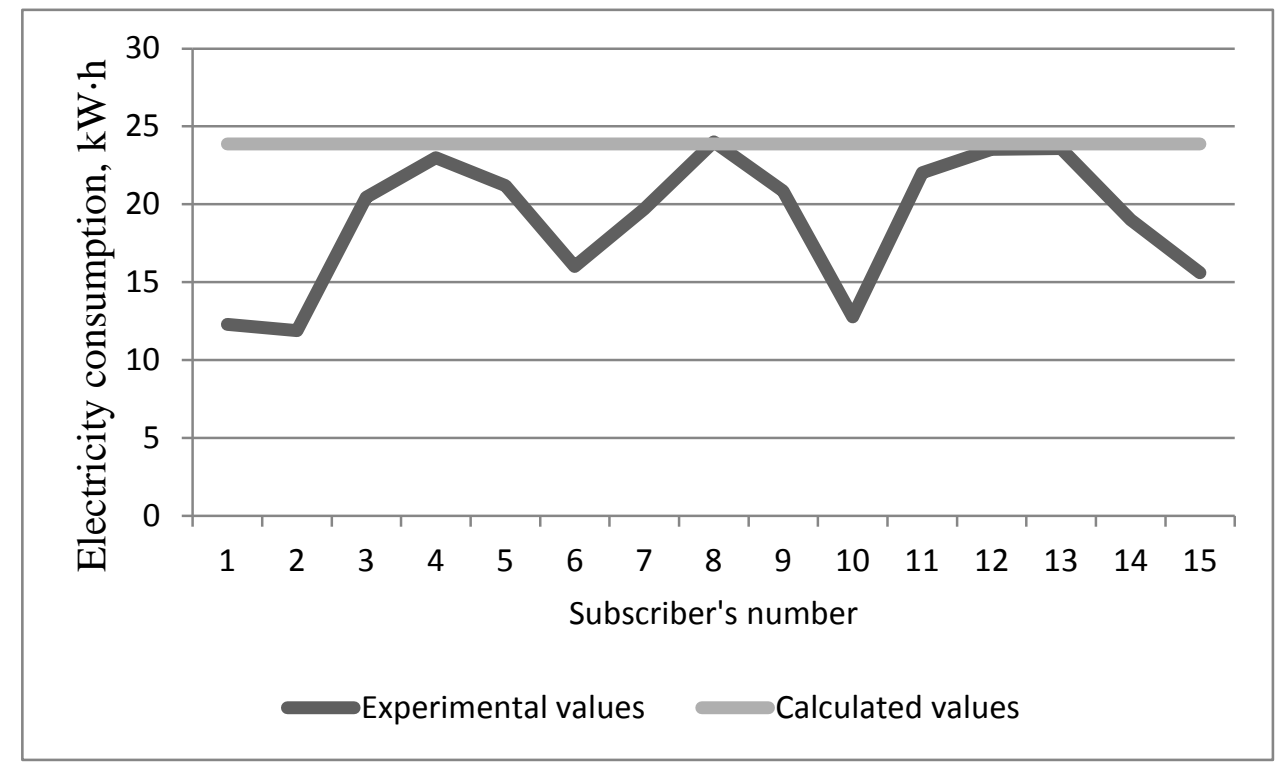

Figure 7. Comparison of data obtained by calculation and experimentally for household consumers who use TS-739, Dushanbe city

\section{RESULTS AND DISCUSSION}

Thus, we would like to offer the following electricity consumption standards controlling algorithm both within the hours of maximum loads and during the whole day and month for the cities of the Tajikistan Republic adding this algorithm into the automated system of electric power account Figure 8.

The working principle of the algorithm is presented below. Information received from the electric power accounting is transmitted to the data center union (DCU) with the help of RS-485 wires. Then a SIMcard connected with the Internet is installed into the DCU to transmit the information from DCU to the information collection center. Information, which is transmitted from the DCU to the information collection center is transferred with the help of wireless wide area network (WAN). For comfortable control we suggest to place information collection centers in the central dispatching office of «Barqi Tojik» and in operational dispatching services of regional and municipal electricity networks of the Republic of Tajikistan.

Conditions of consumption and electricity consumption standarts compliance of residential consumers in cities of the Republic of Tajikistan.

In accordance with the conditions of electricity consumption within overloaded hours, during a day and a month:

$$
\mathrm{W}_{\alpha_{\text {t.m.l. }}+1}=\mathrm{W}_{\text {stand }}
$$


where $=\mathrm{W}_{\alpha_{\text {t.m.l. }}+1}=$ electricity consumption forecast, $K w h ; \quad \mathrm{W}_{\text {stand }}=$ electricity $\quad$ consumption standard $K w h,[1,2]$.

Gathered information is automatically transmitted to preserve it. If $\mathrm{W}_{\alpha_{\mathrm{t} . \mathrm{m} . \mathrm{l}}+1}>\mathrm{W}_{\text {stand }}$, then the information about consumers' data is taken under control and within 3 days this particular consumer's data is being supervised, especially during the hours of maximum loads. That is because particularly this time a large part of electric power is consumed, consequently, general overloads are observed. Their data is saved to the information collection center too. If within 3 days condition $\mathrm{W}_{\alpha_{\mathrm{t} \text {.m.l. }}+1}>\mathrm{W}_{\text {stand }}$ doesn't turn into $\mathrm{W}_{\alpha_{\mathrm{t} . \mathrm{m} . \mathrm{l}}+1} \leq \mathrm{W}_{\text {stand }}$, subscriber is notified about electricity consumption oversupply. We assume that this kind of notification will encourage both electric power consumers and the control of electric power system reliability.

The following day after the warning, electricity consumption is controlled again, especially during the period of maximum loads. In case of $\mathrm{W}_{\alpha_{\mathrm{t} . \mathrm{m} . \mathrm{l}}+1} \leq \mathrm{W}_{\text {stand }}$ condition is fulfilled, information is transmitted for its further saving.

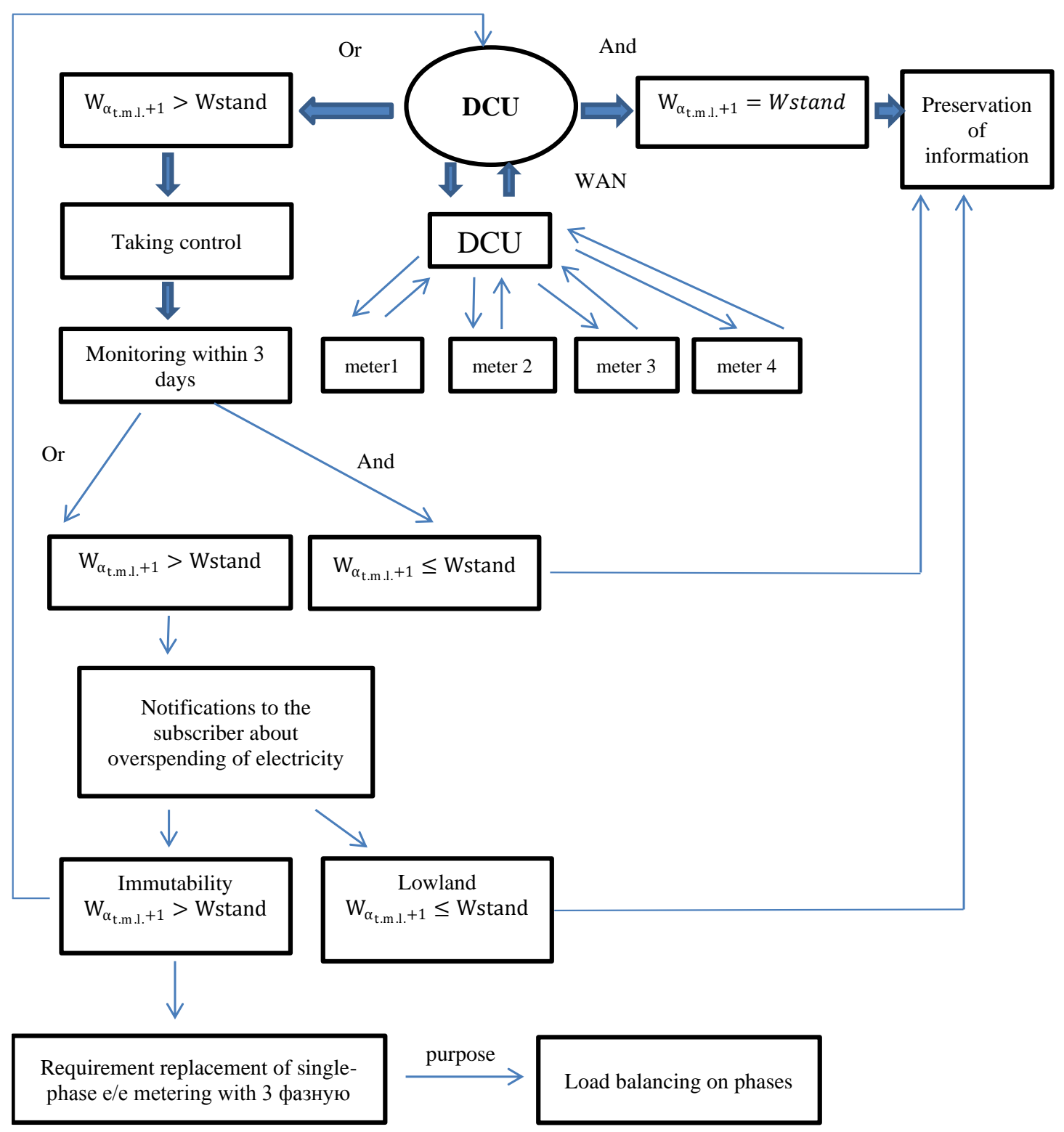

Figure 8 . The algorithm of electricity consumption control

However, in case of the further non-compliance of electricity consumption standards, subscriber will be given a recommendation considering the replacement of single-phase electronic meter by a three-phase 
one. Recommendation is given so that to improve the reliability of electricity supplies, increase the quality of electric power and reduce the shortfall of the net power. Thus, schematic execution of data reception and transmission through the channel of WAN from automatic electricity accounting to «Data Center Union» and from «Data Center Union» to the center of information gathering as shown in Figure 8 was suggested on the basis of the electricity consumption control algorithm as shown in Figure 9. The suggested scheme of information reception and transmission from a subscriber to the information collection center was recommended by electric power supplying organization-a public limited company «Barqi Tojik» for implementation of replacement of the current account of electric power by the automated one into the programme.

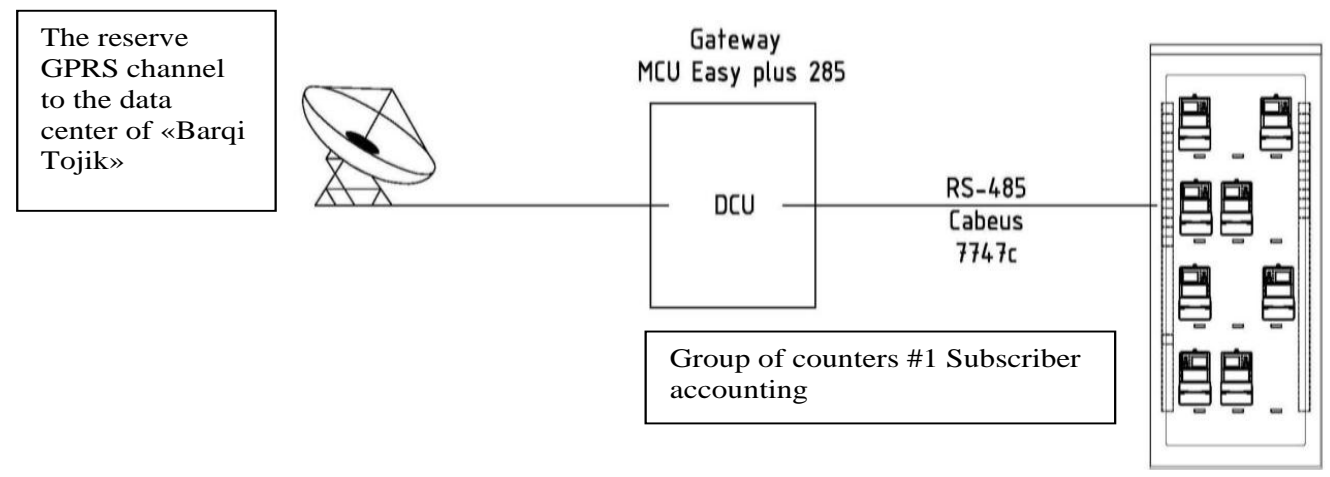

Figure 9. The Scheme of information reception and transmission from a subscriber to the information collection center

\section{CONCLUSION}

According to a statistical analysis of the outage occurrence of electrical equipment in urban distribution electric networks in Dushanbe for the periods of 2017-2018 and for reasons of distribution damage resulting in outage shutdown data, factors have been identified that affect the reliability of power supply to the electrical network in Dushanbe. Taking into account the identified factors, the electricity consumption prediction equations are proposed taking into account the terrain of the city of Dushanbe, the introduction of which into the control algorithm based on the functionality of smart electricity metering, it is possible to maintain operational parameters of the electric network thereby increasing the reliability of the city electric network of Dushanbe.

\section{REFERENCES}

[1] A. I. Sidorov and S. Sh. Tavarov, "Dependencies of specific load on electricity consumption taking into account the peculiarities of the Republic of Tajikistan," Scientific and technical journal "Energy of the unified network", vol. 3, no. 45 , pp. 70-75, 2019.

[2] S. Tavarov, "Specific power consumption of the domestic sector taking into account the ambient air temperature and the territorial location of the Republic of Tajikistan," Industrial power engineering, no. 7, pp. 19-22, 2019.

[3] Z. Yahia and A. Pradhan, "An optimal load schedule of household appliances with leveled load profile and consumer's preferences," 2018 International Conference on the Domestic Use of Energy (DUE), Cape Town, pp. 1-7, 2018.

[4] Z. Yahia and P. Kholopane, "A binary integer programming model for optimal load scheduling of household appliances with consumer's preferences," 2018 International Conference on the Domestic Use of Energy (DUE), Cape Town, pp. 1-8, 2018.

[5] G. Grigoras and F. Scarlatache, "Processing of smart meters data for peak load estimation of consumers," 2015 9th International Symposium on Advanced Topics in Electrical Engineering (ATEE), Bucharest, pp. 864-867, 2015.

[6] T. Teeraratkul, D. O’Neill and S. Lall, "Shape-Based Approach to Household Electric Load Curve Clustering and Prediction," in IEEE Transactions on Smart Grid, vol. 9, no. 5, pp. 5196-5206, Sep 2018.

[7] S. Singh, A. Roy and M. P. Selvan, "Smart Load Node for Nonsmart Load Under Smart Grid Paradigm: A New Home Energy Management System," in IEEE Consumer Electronics Magazine, vol. 8, no. 2, pp. 22-27, March 2019.

[8] H. Swalehe and B. Marungsri, "Intelligent Algorithm for Optimal Load Management in Smart Home Appliance Scheduling in Distribution System," 2018 International Electrical Engineering Congress (iEECON), Krabi, Thailand, pp. 1-4, 2018. 
[9] N. Mohan, T. P. Imthias Ahamed and J. M. Johnson, "Demand Side Management for a Household Using Resource Scheduling," 2018 International CET Conference on Control, Communication, and Computing (IC4), Thiruvananthapuram, pp. 1-5, 2018.

[10] A. Garulli, S. Paoletti and A. Vicino, "Models and Techniques for Electric Load Forecasting in the Presence of Demand Response," in IEEE Transactions on Control Systems Technology, vol. 23, no. 3, pp. 1087-1097, May 2015.

[11] I. Opriş, S. Costinaş, C. Ionescu and D. Nistoran, "The household energy consumer in a smart metering environment," 2015 9th International Symposium on Advanced Topics in Electrical Engineering (ATEE), Bucharest, pp. 43-48, 2015.

[12] J. Kim, J. Han, N. Kim, M. Kim and J. Choi, "Analysis of power usage at household and proper energy management," 2018 International Conference on Information and Communication Technology Convergence (ICTC), Jeju, pp. 706-708, 2018.

[13] A. I. Sidorov, O. A. Khanzhina, S. S. Tavarov and M. S. Osimi, "Ensuring the Efficiency of Distribution Networks C. Dushanbe and Republic of Tajikistan," 2019 International Multi-Conference on Industrial Engineering and Modern Technologies (FarEastCon), Vladivostok, Russia, pp. 1-4, 2019.

[14] L. Florence et al., "Vapniks learning theory applied to energy consumption forecasts in residential buildings," International Journal of Computer Mathematics, vol. 85, no. 10, pp. 1563-1588, 2007.

[15] Nataliya G. Repkina, "Research of factors affecting the accuracy prediction daily power consumption," Russian Electromechanics, no. 2, pp. 41-43, 2015.

[16] V.A. Zubakin and N.M. Kovshov, "Methods and analysis models of electricity consumption in view of cyclicity and stochastics," Business Strategies, vol. 7, no. 15, pp. 24-29, 2015.

[17] V. E. Vorotnitsky, "About digitization in economics and power industry," Energetik, no. 12, pp. 6-14, 2019.

[18] V. E. Vorotnitsky and Yu. I. Morzhin "Digital transformation of energy in Russia -a system task of the fourth industrial revolution," Scientific and technical journal. Energy of the unified network, vol. 6, no. 42, pp. 12-21, 2018.

[19] Supriyadi, Edi Rakhman, Suyanto, Arif Rahman, Noor Cholis Basjaruddin, "Development of a Wireless Power Transfer Circuit Based on Inductive Coupling," TELKOMNIKA Telecommunication, Computing, Electronics and Control, vol. 16, no. 3, pp. 1013-1018, June 2018.

[20] Hartono BS, Sri Paryanto Mursid, Sapto Prajogo, "Comparative Study Improving Residential Load Factor Using Power Shifting and Load Shifting," TELKOMNIKA Telecommunication, Computing, Electronics and Control, vol. 16, no. 4, pp. 1396-1403, Aug 2018.

[21] Rezzy Eko Caraka, Sakhinah Abu Bakar, Gangga Anuraga, M. A. Mauludin, Anwardi Anwardi, Suwito Pomalingo, Vidila Rosalina, "The step construction of penalized spline in electrical power load data," TELKOMNIKA Telecommunication, Computing, Electronics and Control, vol. 17, no. 2, pp. 1023-1031, April 2019.

[22] Galih Bangun Santosa, Setiyo Budiyanto, "New design of lightweight authentication protocol in wearable technology," TELKOMNIKA Telecommunication, Computing, Electronics and Control, vol. 17, no. 2, pp. 561-572, April 2019.

[23] Fernando Martínez Santa, Fredy H. Martínez, Edwar Jacinto, "Risk simulation of having direct contact with electric urban networks," TELKOMNIKA Telecommunication, Computing, Electronics and Control, vol. 17, no. 5, pp. 2276-2284, Oct 2019.

[24] S. M. Salim Reza et al., "Salsa20 based lightweight security scheme for smart meter communication in smart grid," TELKOMNIKA Telecommunication, Computing, Electronics and Control, vol. 18, no. 1, pp. 228-233, Feb 2020.

[25] G. S. Valeev et al., "Modeling of daily load schedules of 6-10 kV distribution network sections in cities and localities under conditions of limited initial information," Bulletin Of SUSU. A Series Of "Energy, vol. 16, no. 2, pp. 23-29, 2016.

\section{BIOGRAPHIES OF AUTHORS}
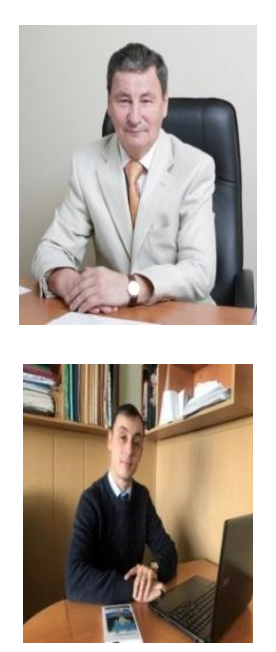

Alexander Ivanovich Sidorov he is currently a Doctor of Technical Sciences, Professor, Head of the Department of Life Safety, Polytechnic Institute, Engineering Faculty of the South Ural State University (National Research University), Russia, Member of the Russian Ecological and International Academy of Sciences. He has published over 400 scientific papers. Its h-index is in elibrary. ru is 8 and 3 in Scopus, and the number of links in WoS exceeds 30. The research area is aimed at improving electrical safety in urban and industrial electrical networks. He is a member and deputy chairman of the dissertation council for the defense of candidate and doctoral dissertations. Member of the editorial board of Life Safety.

Saidjon Tavarov currently a doctoral candidate, candidate of technical sciences, associate professor of the Department of Life Safety of the Polytechnic Institute, Faculty of Engineering of the South Ural State University (National Research University), Russia and associate professor of the Department of Power Supply, Department of Energy, Tajik Technical University University named after academician M.S. Osimi, Republic of Tajikistan. He has published over 45 scientific papers. . Its h-index is in elibrary. ru is 4 and in Scopus - 1, and the number of links in WoS exceeds 3. The research area is aimed at improving the reliability of urban electrical networks. He is a member of the editorial board of the International Research Journal. 